\title{
Diversidad cultural y evangelio de los pobres
}

\author{
F. Javier Vitoria Cormenzana, \\ Instituto Diocesano de Teología y Pastoral, Bilbao, \\ Centro de Reflexión Teológica, San Salvador.
}

\section{Planteamiento}

El tercer milenio se ha convertido en la referencia obligada para el caminar de la Iglesia en este fin de siglo. En noviembre de 1994 Juan Pablo II, en su carta apostólica Tertio Millenio Adveniente (TMA), la invilaba a preparar el jubileo 2000. La conmemoración de los dos mil años del nacimiento de Jesús de Nazaret se presenta como una oportunidad de salvación, en la que cada uno ha de hacer cuanto esté en su mano para no desaprovecharla (TMA 55). Han pasado tres años desde entonces y nos disponemos a iniciar el segundo año de la fase preparatoria, que se dedicará de modo particular al Espiritu Santo y a su presencia santificadora dentro de la comunidad de los discípulos de Cristo (TMA 44). Las iniciativas eclesiales que secundan la invitación papal se multiplican en toda la Iglesia universal, y las diversas propuestas papales ordenadas a la mejor preparación del jubileo van cumpliéndose puntualmente'.

El año 2000 es una fecha repleta de significado simbólico. Más allá de las expectativas milenaristas y los temores que este tipo de guarismos hayan suscitado en el pasado y puedan provocar hoy todavfa, el aniversario bimilenario del natalicio de aquel hombre que "abrió una brecha en la conciencia de la humanidad" (R. Garaudy) es capaz, por si solo, de desatar, tanto en la vida de los cristianos como indirectamente en la de gran parte de la humanidad, un sinfín de recuerdos, de convocatorias y de propuestas con un denso contenido humano y evangélico (TMA 15). Celebrar ritualmente los aniversarios de aquellos acontecimientos, personales, comunitarios, inslitucionales o históricos, que resultaron cruciales es algo profundamente humano. El recuerdo permite tenerlos presentes revivirlos y no olvidarlos. Pero además, y de un modo aún más profundo, posibilita el que uno mismo vuelva a vivir gracias a la energía liberada por aquella

1. En el momento de redactar este trabajo se está celebrando en Roma el sínodo panamericano sobre la problemática de la nueva evangelización en las dos partes del mismo continente (TMA 38). 
memoria y en conformidad con lo que ella nos entrega. Recordar es una actividad del corazón humano, nada emparentada con la memoria de las computadoras. Bien lo saben los miles de cristianos salvadoreños, hombres y mujeres, laicos y presbíteros, campesinos y universitarios, niños, jovenes y ancianos, que cada año recuerdan que en El Salvador y Centroamérica "la Iglesia ha vuelto de nuevo a ser Iglesia de los mártires", impidiendo así que el testimonio de quienes también en nuestro tiempo han vivido plenamente la verdad de Cristo se pierda en ella (TMA 37).

En la tradición judeo-cristiana este ejercicio anamnético responde a una honda comprensión teologal de la historia. "En el cristianismo -como escribe el papa- el tiempo tiene una importancia fundamental. Dentro de su dimensión se crea el mundo, en su interior se desarrolla la historia de la salvación, que tiene su culmen en la 'plenitud de los tiempos' de la encarnación y su término en el retorno glorioso del hijo de Dios al final de los tiempos. En Jesucristo. Verbo encarnado, el tiempo llega a ser dimensión de Dios, que en sí mismo es eterno [...] Cada año, cada día y cada momento son abarcados por su encarnación y resurrección, para de este modo encontrarse de nuevo en la "plenitud de los tiempos'"(TMA 10). Por ello mismo, la teología, como inteligencia de la fe, ha de estar siempre dispuesta a escrutar los signos de los tiempos (y de este tiempo que se avecina), poniendo en práctica el programa teológico propuesto por el concilio Vaticano II (GS $4 ; 11 ; 44)$, acontecimiento providencial, gracias al cual la Iglesia inició la preparación próxima del jubileo del segundo milenio (TMA 18).

En este contexto, este trabajo se pregunta ¿qué nos dice este tiempo? e intentará vislumbrar en el espesor teológico del momento histórico algunas de las tareas que corresponden a las exigencias del anuncio del evangelio ${ }^{2}$. Quizás la característica que mejor lo define sea ese proceso de transformación, permanente, vertiginoso y profundo, que va alectando a codas las dimensiones de la realidad (cultural, social, económica, política y religiosa). Entre brumas empezamos a vislumbrar el rostro de la nueva era, pero nos resulta imposible distinguir y perfilar sus rasgos concrelos. La visión se enturbia no solamente como consecuencia del vértigo que producen las constantes aceleraciones históricas, sino además por el carácter sumamente conlliclivo y problemálico de lo que está aconteciendo. El futuro de la humanidad, permílaseme la imagen, se encuentra literalmente "a los pies de los caballos" de los modernos jinetes del Apocalipsis: la bomba de la pobreza. la crisis ecológica, el paro estructural y el conflicto latente o patente entre culturas.

Esta rellexión va a lomar como cuestión de este tiempo este último desafío. Además de la imposibilidad para abordar todas los interrogantes que el momento presente plantea a la teología, tanto en la instancia de la urgencia como en la de la búsqueda", tengo otros dos motivos. Uno: precisamente el jubileo del año

2. Cfr. G. Gutiérrez. "La teología de la liberación en el contexto del tercer milenio". en Consejo Episcopal Latinoamericano. El fusuro de la reflexión seológica en América Latina, CELAM, Colombia, 1996, pp. 101-102.

3. Cfr., A. Torres Queiruga, "Responsabilidad de los cristianos en el mundo actual". Cristianismo y Sociedad, 128, (1996), p. 33. 
2000 se nos presenta como una oportunidad para meditar sobre la dificultad del diálogo entre diversas culturas, que se reconoce como uno de los desaffos del momento (TMA 51). Dos: a partir del Vaticano II, el magisterio de Pablo VI y de Juan Pablo II, en especial, ha insistido "a tiempo y a destiempo" sobre la necesidad del diálogo entre fe y cultura o de la inculturación del evangelio ${ }^{4}$. Particular intensidad en el proyecto de nueva evangelización ha adquirido la (justa y pertinente) reivindicación eclesial de las raíces cristianas de la cultura europeo-occidental en el contexto secular y agnóstico de las sociedades desarrolladas. Sin embargo, no siempre se advierte con la misma clarividencia que dicha reclamación supone un serio ejercicio de autocrítica del movimiento misional modernos. El cristianismo ha legitimado (los intereses coloniales que se ocultaban tras la falsa pretensión de superioridad de) la cultura y las tremendas agresiones y violencias ejercidas sobre otras consideradas inferiores por el mero hecho de ser diferentes. Consecuentemente, ha de asumir las responsabilidades contrádas por los efectos mortíferos (etnocidio y genocidio) de la expansiva política cultural de occidente. El papa sugiere a los hijos de la lglesia que, con ánimo abierto al arrepentimiento, vinculen su meditación sobre los conflictos culturales a la memoria de "la aquiescencia manifestada, especialmente en algunos siglos, con métodos de intolerancia $e$ incluso violencio en el servicio a la verdad". De ese capitulo doloroso de nuestra historia eclesial "emerge una lección para el futuro, que debe llevar a todo cristiano a tener buena cuenta del principio de oro dictado por el concilio: 'La verdad no se impone sino por la fuerza de la misma verdad, que penetra, con suavidad y firmeza a la vez, en las almas'" (TMA 35). En esta revisión histórica no hay ningún afán patológico o ingenuo de victimación por los errores del pasado, sino la pretensión de sacar enseñanzas de nuestra historia que puedan servir para construir más humana y evangélicamente la del próximo milenio.

El cristianismo comparte con la cultura occidental el desafío de ser capaz. teórica y prácticamente, de expresar y de vivir la diferencia en la igualdad. Para afrontarlo con éxito necesitará algo más que contar a medias la verdad de su historia y reconocer a destiempo el haber utilizado métodos de intolerancia e incluso de violencia en el servicio de la verdad. Sin embargo, parece que la

4. Puede verse una síntesis de toda esta producción con los aportes latinoamericanos en C. M. Galli, La teología latinoanericana de la cultura en las visperas del tercer milenio, Consejo Episcopal Latinoamericano, op. cir., pp. 243-362.

5. "Lo trágico de ese gran movimiento misional moderno del cristianismo fue que el entusiasmo desbordado, el espíritu emprendedor y la disposición al sacrificio desinteresado de tantos misioneros y de sus Iglesias locales discurrí en el horizonte aceptado inconsciente y acríticamente (no siempre, pero la más de las veces). del etwocentrismo, que nacía de la obvia superioridad de la cultura europeo-occidental; por eso se 'exportó' ésta. muchas veces. en la unidad indiferenciada con la fe cristiana. Sólo desde los mediados de nuestro siglo [...] lue rechazada general y radicalmente esa mentalidad eurocéntrica, y esto tuvo lógicamente notables consecuencias para la misión de la Iglesia". M. Kehl, La Iglesia. Eclesiología carólica. Salamanca. 1996, pp. 230-231. 
Iglesia, con independencia de su voluntad, no podrá en el futuro imponer la verdad por la fuerza. Gracias al laicismo de los estados modernos, carece de los instrumentos coercitivos que el poder político (el imperio) le prestó en el pasado. Esta obviedad nos permite ahondar en la reflexión papal.

Realmente, muchas cosas han cambiado con respecto al pasado en el modo cómo la Iglesia ofrece su verdad a los hombres y mujeres de este final de milenio. El Vaticano II con su reconocimiento público del derecho de las personas y de las comunidades a la libertad social y civil en materia religiosa fue el responsable de este giro en su talante misionero. Pero quedan bastantes cuestiones abiertas: ¿no sigue apareciendo la Iglesia católica, primordialmente, como una "Iglesia occidental" que lleva su lengua y $s u$ forma de fe, liturgia y vida comunitaria y teología a los antiguos países de misión y las implanta allí con una ligera adaptación local? ${ }^{\text {. }}$ ¿Su oferta evangelizadora (cristalizada principalmente en su paradigma premoderno)" no sigue "exportando" la cultura occidental en una unidad indiferenciada con la fe cristiana? ¿El método de diálogo e inculturación que practica con y en otras culturas no se encuentra viciado por el viejo esquema de la superioridad y la subordinación, ahora desprovisto de "la fuerza disuasoria" del poder secular? ¿No es esta hipoteca la que impide que junto a la figura occidental del cristianismo vayan surgiendo y adquiriendo carta de naturaleza en la communio ecclesiarum sus figuras asiáticas, africanas, latinoamericanas y oceánicas?

En nuestra reflexión recurriremos al pensamiento de Bartolomé de las Casas. Accederemos a él a través de dos lecluras de su obra, realizadas desde dos perspectivas que responden a intereses personales e intelectuales muy diferentes. Una, latinoamericana, creyente y teológica; ${ }^{\mathrm{R}}$ la otra, europea, laica y filosofico política". Aquel "encomendero de la buena nueva", como poéticamente lo Ilama P. Casaldáliga, fue un testigo excepcional de su tiempo y de los inicios

6. Cfr. ibid., pp. 193-194.

7. La inculturación de la fe cristiana en la cultura occidental se encuentra fijada en una época histórica. El cristianismo ha sido y sigue siendo una religión vivida en occidente, pero no podemos estar tan seguros de que sea una religión viva, ya que se ha resistido y se sigue resistiendo a expresarse en esa cultura in staru nascendi que se va abriendo paso a partir de la modernidad. Mi balance final indica que, en plena transmodernidad, el catolicismo oficial se encuentra todavía sin resolver su confrontación con la modernidad ilustrada y resistiéndose a salir del paradigma católicoromano medieval. Resulta muy interesante la rendición de cuentas crfíca que realiza H. KUng en su libro El cristianismo. Esencia e historia, Madrid, 1997, de veinte siglos de historia del cristianismo y de sus confrontaciones con cinco paradigmas culturales diferentes: el judeocristiano-apocalíptico, el helenístico-bizantino-ruso, el católico-romano medieval, el reformador-protestante y el moderno-ilustrado.

8. Cfr. G. Gutiérrez. En busca de los pobres de Jesucristo. El pensamiento de Bartoloiné de Las Casas, Salamanca, 1993.

9. Cfr. F. Fernández Buey, La gran perturbación. Discurso del indio metropolitano, Barcelona, 1995. 
del movimiento misional moderno, cuando la interdependencia entre la cruz y la espada fue la moneda más habitual en la penetración del Evangelio. Su búsqueda "de los pobres de Jesucristo" lo transformó en un resistente frente de la "teodicea beligerante" que practicó entonces el cristianismo, centrada en los intereses de occidente, aliada de la ideología colonial y justificadora de los estragos y acabamientos de aquellos pueblos indígenas. En aquellos tiempos de singular intolerancia y violencia, Las Casas puso sin descanso su vida al servicio de la vía de "la mansedumbre y la suavidad" en la evangelización frente a la vía armada. Como un profeta desarmado, combatió hasta su muerte contra una estrategia misionera que significaba la desestructuración simbólica de las culturas y de las religiones de ultramar como consecuencia de que prácticamente se juzgaban de modo negativo las posibilidades intelectuales y morales de las poblaciones autóctonas. El propio testamento lascasiano califica los atropellos de "la conquista" como "escándalos e infamias de nuestra fe". El resultado de semejante desaguisado es el sincretismo religioso que hoy alberga América Lalina en lugar de una auténtica inculturación del evangelio. Y es que una recreación significativa de la religión cristiana resulta del todo imposible, cuando los miembros de un determinado grupo social tienen conciencia de "vencidos"1u. Desde el punto de vista de la filosofía política, Las Casas tiene una visión de lo que ocurre al entrar en conllicto con la racionalización o legitimación de aquel primer colonialismo moderno que ponía el acento en la superioridad cultural de los europeos cristianos: un acercamiento novedoso a los problemas del paria y un concepto radical de la comprensión de la alteridad. Aun reconociendo la necesidad de eliminar sus impurezas teocráticas y paternalistas, la propuesta lascasiana encierra una enorme fecundidad para nuestro presente. Hace falta recuperar un pensamiento como el suyo, que invierte el tradicional argumento eurocéntrico y contribuye a la conformación inicial de la conciencia moderna de especie, para tiempos en los que, descubierto ya por la modernidad que la caridad es insuficiente para cambiar de base un mundo de injusticias y desigualdades, empezamos a descubrir que la crílica de la caridad, sin más, tampoco es suficiente".

\section{2. "Un nuevo mundo" y otra vez los viejos conflictos premodernos}

Se ha dicho que el siglo XXI comenzó en 1989. Los acontecimientos (disolución del bloque soviético y la caída del muro de Berlín) de aquel año trajeron consigo la solución pacífica al creciente peligro atómico de la "guerra fría" y una nueva ordenación geopolítica del mundo. Fueron sucesos tan sorprendentes por su envergadura y rápido desarrollo que se ha podido percibir en ellos la intervención de la materna mano invisible de la Providencia, a pesar de que después hayan surgido nuevos peligros y nuevas amenazas (TMA 27). Se esperaba que trajeran consigo "un nuevo mundo". Voces interesadas se apresuraron

10. Cfr. Ll. Duch. Religión y mundo modemo. Introducción al estudio de los fenómenos religiosus. Madrid. 1995, pp. 261, 366-374.

I1. Cfr. F. Fernández Buey, Lo gran periurbación..., pp. 26 y 40. 
a anunciar que había llegado el fin de la historia, el tiempo de la universalización, ampliación y profundización de la democracia. En realidad, las cosas han ido por otros derroteros. Con sorpresa nos hemos encontrado otra vez con viejos conflictos de identidad, que creíamos asunto del pasado. "A cualquier parte adonde uno dirija su mirada allí está la guerra entre etnias, la xenofobia, el racismo el ataque cultural. La impresión que el mundo da es que las gentes tienden a subordinar los intereses económicos y sociales, que un día aproximaban a los individuos en el seno de las clases sociales, para volver a fijarse, una vez más. en los colores de sus pieles, en las diferencias entre sus costumbres. en los hábitos del otro, en la diversidad de las lenguas [...] Pueblos en los que hace no muchos años convivlan y se mezclaban gentes de diferentes culturas (con problemas, sí; con diferencias latentes. claro; y a través de no pocos sentimienlos por aquello de 'estar vosotros en nosotros y nosotros en vosotros', desde luego) se han convertido de pronto en un infierno en el que, por ejemplo, sentirse dos o tres cosas a la vez, o creer tener tres identidades al mismo liempo. equivale a estar muerto; y muerto por aquellos mismos, un día prójimos, que niegan ahora, de repente, que se pueda ser más de una cosa en este mundo [...] Etnias, religiones y naciones que por lo general observan con indiferencia o con discreto desprecio el crecimiento del imperio único no pueden, en cambio, soportar la diversidad del vecino de al lado y sus implicaciones políticas"1?

\section{"Los demonios de un nuevo tribalismo se han desatado"}

Se mire por donde se mire, el mapamundi parece como si los viejos demonios del tribalismo se hubieran desatado. La enumeración de todas las situaciones de emergencia humanitaria que estos conflictos han generado en los últimos ocho años sería interminable. Pero resulta sencillo recordar algunos de sus cscenarios y el espanto que producen esos infiernos, donde sc calcina interminablemente la humanidad y su dignidad: el horror de la guerra que ha cnfrentado a serbios, croatas y bosnios en la antigua Yugoslavia; los miles de muertos producidos por los conflictos interétnicos en Africa; las masacres humanas del fundamentalismo argelino; los sufrimientos y las enormes pérdidas humanas producidos por el conflicto judeo-palestino, el tibetano con China, el saharaui con Martuecos, el kurdo con Turquía, el checheno con la Federación Rusa, el de los tamiles en Sri Lanka o el de los dalits en la India; las víctimas de la violencia en Irlanda y el País Vasco; los atentados contra inmigrantes que tienen lugar cotidianamente en tantos países europeos y norteamericanos; las colisiones constantes que se producen en la selva amazónica, donde lo premoderno, lo moderno y lo postmoderno compiten a veces sin reconocerse como tales; las agresiones contra los indigenas guatemaltecos, ecuatorianos, australianos; la larga guerra no declarada de Perú; el inesperado levantamiento indígena en Chiapas; la cadena causal, cada vez más patente, entre explotación económica, supervivencia del campesinado indígena, economía de la droga, violencia primitiva que casi siempre toma la forma de la matanza de los pobres, malestar

12. F. Fernández Buey, La gran perturbación.... pp. 18-22. 
cultural y sociedad policial posmoderna"'. Para qué scguir...

\section{El choque de culturas}

Toda esta geografía del horror avala la tesis de muchos analistas sociales que afirman que la conflictividad social en el plano internacional se está configurando como choques entre culturas. Quizás la teoría más conocida - y tambiến más discutida- sea la de Samuel Huntington ${ }^{14}$. En su opinión, la dimensión fundamental y más peligrosa de la política global que está surgiendo es el conflicto entre civilizaciones diferentes. El sentimiento de pertenencia a una civilización va cobrando más y más importancia en un mundo que está atravesado por la interacción de siete civilizaciones mayores: china, japonesa, hindú, islámica, occidental, latinoamericana y (posiblemente) africana. En el tiempo de la postguerra fría, la cultura y las identidades culturales son las que configuran las pautas de cohesión, desintegración y conllicto social. En la medida en que las grandes ideologías políticas del siglo XX (jpor cierto, todas ellas occidentales!) declinan, su lugar va siendo ocupado por las religiones ( civilizaciones no occidentales!) y otras formas de identidad basadas en la cultura. El choque intracivilizatorio de las ideas políticas generadas por occidente, está siendo sustituido por un choque de cultura y religión entre diversas civilizaciones. Las distinciones más radicales entre los pueblos han dejado de ser ideológicas, políticas y económicas para convertirse en culturales. "Las líneas de fallas" entre las diversas civilizaciones serán los frentes de batalla del futuro. $Y$ todo ello por una razón: las personas y las naciones están intentado responder a la pregunta más básica que los seres humanos podemos afrontar: iquiénes somos'? Las religiones jugarán un papel principal en todos estos terremolos sociales's, pues constituyen una característica definitoria básica de las civilizaciones, siendo la cristiana (en sus versiones católica y protestante) la característica más importante de la civilización occidental, que, jatención!, protagoniza una invasión cultural a escala mundial ${ }^{16}$.

\section{La "des-occidentoxicación" de la aldea global}

La oposición ante semejante violencia cultural" ${ }^{17}$ está dando lugar a una ola

13. Cfr. F. Fernández Buey. La barbarie: de ellos y de los nuestros, Barcelona, 1995; F. Houtart, "El culto a la violencia en nombre de la religión: un panorama", Concilium 272 (1997), pp. 617-627.

14. Cfr. El choque de civilizaciones y la reconfiguración del orden mundial, Barcelona-Buenos Aires-México, 1997.

15. Otros nolables observadores e interpretes de la realidad social también han subrayado el papel que las religiones juegan o pueden jugar en estos conflictos de identidad: H. Küng, Proyecto de una ética mundial, Madrid, 1991; R. Panikkar, Paz y desarme cultural. Santander, 1993; R. Garaudy, ¿Hacia una guerra de religión? El debare del siglo. Madrid, 1995: "La religión ¿fuente de violencia?", Concilium 272 (1997).

16. Cfr.. S. P. Huntington, op. cit., pp. 1-81.

17. "Occidente conquistó el mundo. no por la superioridad de sus ideas. valores o 
de indigenismo y de resurgimiento de las culturas no occidentales, que recorre nuestro mundo. Pero con ella las banderas y otros símbolos de identidad cultural (como las cruces, las medias lunas, los modos de cubrirse la cabeza, las religiones, etc.) han recobrado una inusitada importancia. Personas individuales y grupos humanos descubren identidades nuevas o viejas, por las que están dispuestos incluso a hacer guerras contra enemigos nuevos o viejos. Cada vez más frecuentemente occidente recibe como respuesta la negativa de las otras culturas a identificar modemización con occidentalización. Una y otra vez le recuerdan que su creencia en la universalidad de su cultura es falsa (porque desprecia el hecho de la diversidad cultural), inmoral (porque oculta en su interior la pretensión de un poder imperialista), y peligrosa (porque mantiene de manera fundamentalista el carácter innegociable de valores como el progreso, la tecnología, la democracia y, sobre todo, el mercado económico mundial). Los movimientos de rechazo y revancha frente a lo que consideran occidentoxicación van en aumento, aunque hayamos de reconocer que traen consigo el peligro de la xenofobia y el racismo, del sectarismo y el autoritarismo. de la dictadura religiosa y la guerra santa's.

\section{"Clonación" cultural y universalismo de la cocacola}

Occidente promueve tan pertinaz como avasalladoramente el modelo cultural norteamericano por todo el mundo. El intento recuerda espontáneamente la clonación de la oveja Dolly: el norte rico pretende reproducir con una inaudita incontinencia copias idénticas de su modelo cultural por todo el mundo. El encanto y la riqueza de la diversidad van cediendo ante la fulminante ofensiva de la estandarización, la homogeneización y la uniformización. "Todo el mundo percibe a su alrededor que la coartada de la modernidad sirve para que todo se doblegue al nivel de una estéril uniformidad. De un extremo al otro del planeta se impone un estilo de vida parecido, expandido por los medios y prescrito machaconamente por la cultura de masas. De La Paz a Uagadugu, de Kioto a San Petersburgo, de Orán a Amsterdam, las mismas películas, las mismas series televisadas, las mismas informaciones, las mismas canciones, los mismos eslóganes publicitarios, los mismos objetos. la misma ropa, los mismos carros, el mismo urbanismo, la misma arquitectura, el mismo tipo de apartamentos, con frecuencia amueblados y decorados de forma idéntica..."14. Esta clase de universalización o colonización cultural se ha ganado muy merecidamente el calificativo de cocacolonización ${ }^{20}$. La cultura hegemónica, tan bien como engañosamente simbolizada por esa bebida que se promociona como "la chispa de la vida", lo

religión (a los que se convirtieron pocos miembros de las otras civilizaciones), sino más bien por su superioridad en la aplicación de la violencia organizada. Los occidentales a menudo olvidan este hecho; los no occidentales, nunca", ibid.. p. 58.

18. Cfr. ibid., pp. 108-120.

19. I. Ramonet, Un mundo sin rumbo. Crisis de fin de siglo, Madrid, 1997, p. 63.

20. Cfr. A. Pieris, "¿Universalidad del cristianismo?", en Cristianisme i Justicia. "Universalidad de Cristo. Universalidad del pobre. Aportación al diálogo interreligioso", Santander, 1995. p. 162. 
que provoca es muerte, es decir, ernocidio cultural. Su estrategia de "conquista" consigue, gracias a los servicios prestados por las nuevas autopistas de la comunicación, abiertas por las modernas tecnologías, introducir toda una estructura ajena de significados y valores en los pueblos pertenecientes a otras culturas, que contribuyen a minar aún más su seguridad social y cultural ${ }^{21}$. Esta situación de indefinición y perplejidad cultural que tantas gentes experimentan en nuestra aldea global recuerda el malestar y los inconvenientes del estar nepantla, sin identidad, por el forzado o no querido "estar vosotros entre nosotros y nosotros entre vosotros", que le dicen a Felipe II los notables indigenas de Tacoplan (Tacuba), en una carta, en la cual solicitan, además, al rey el apoyo de Las Casas $^{22}$.

\section{"Civilización del mercado" y relaciones sociales precapitalistas}

Esta perspectiva de la conflictividad social internacional no es aceptada por algunos de los que sostienen que ya no hay más que una única civilización: la del capitalismo. En mi opinión, ambas perspectivas son complementarias y no deberían enfrentarse dilemáticamente. La situación de los pobres del mundo no está para debates sobre "galgos o podencos". Nuestro análisis ha de ir a las causas profundas de estos conflictos culturales para no quedarnos en las apariencias. Cualquier diagnóstico que se apoye solamente en la perspectiva socioeconómica o no vaya más allá de una explicación cultural o religiosa se queda en la superficic. Hemos de evitar las simplificaciones y establecer lúcidainente una indisoluble relación entre conflictos culturales, pobreza en el mundo y paz social. Gustavo Gutiérrez nos ha advertido que tener en cuenta la dimensión socioeconómica de la pobreza es muy importante, pero que es necesario ir más lejos y saber entrecruzarla con el punto de vista cultural para poder responder a la complejidad de nuestro mundo ${ }^{23}$. A nadie se escapa que generalmente, los occidentales (ciudadanos de las sociedades ricas) percibimos más extrañeza y mayores peligros en las gentes de las otras culturas en la medida en que son más pobres. La llegada hasta nuestros países de técnicos, expertos, comerciantes, negociantes, arlistas y deportistas extranjeros es siempre un acontecimiento pacífico y deseado al que los media dan la bienvenida. La presencia de las pobres gentes que huyen de la miseria o de la guerra de sus palses y buscan trabajo y condiciones humanas de vida en los nuestros es siempre "una invasión", destinada a desatar las más bajas pasiones, que sutilmente aquellos mismos media manipularán para hacer plausible democráticas legislaciones draconianas de residencia o discriminatorias de deportación ${ }^{24}$. La "arabofobia" que recorre Europa se volatiliza, como por encanto, ante los jeques de los petrodólares, y el temor a los africanos o el desprecio a "los sudacas" se convierte en simpatta y admiración, cuando se trata de "dioses del fútbol", como el liberiano

21. Cfr. UNESCO. Nuestra diversidad creativa. Infonne de la Comisión Mundial de Culiura y Desarrollo, Fundación Santa Maria-SM, Madrid, 1997, p. 46.

22. Cfr. F. Fernández Buey, La gran perrurbación..., pp. 7-8

23. Cfr. "Mirar lejos", Paginas 93 (octubre 1989), p. 82.

24. Cfr. F. Femández Buey, La barbarie..., p. 248. 
Weah o el brasileño Ronaldo.

La globalización autoritaria de la economía de mercado, explotadora y promotora de desigualdades, en lugar de liberar y producir democracia económica, reactiva en las sociedades y sectores periféricos del sistema mundial los conflictos basados en las relaciones sociales precapitalistas. La mayoría de las poblaciones expresan sus frustraciones y sus protestas en las formas que sus culturas les han transmitido. La globalización que reduce toda la realidad humana a la racionalidad del sistema de mercado, reactiva y fortalece formas de conflicto aparentemente tradicionales, pero que de hecho son creadas por el sistema. Las manifestaciones de la reacción violenta, en muchos casos, tendrán expresiones culturales o religiosas, que pueden ser alimentadas por aspectos intrínsecos de éstas, pero no son una simple vuelta a un pasado nostálgico, sino una reconstrucción cultural, con aquellos elementos que esas poblaciones tienen a la mano para afrontar una situación actual de agresión (o violencia) estructural's.

En el siglo XVI, los enviados a América por los reyes españoles, en expresión de Bartolomé de las Casas, "sembraron gran perturbación en todas aquellas naciones", en nombre del derecho de genles y del universalismo cristiano. Hoy, en las puertas del siglo XXI, los servidores y agentes del mercado propagan otra enorme perturbación, esta vez a escala mundial, en nombre de la globalización y sus necesidades ${ }^{2 n}$. El carácler único del mercado, del imperio y (cada día más) del pensamiento ${ }^{27}$ condena a las tinieblas exteriores de la barbarie premoderna a toda manifestación cultural que no se atenga al guión autoritariamente establecido, y está obligando a la mayoría de la humanidad, en Africa, Asia, América Latina y parte de Europa, a vivir inmersa en un complicadísimo proceso de vansculturación. Todo ello ha terminado por configurar la conflictividad social en el plano internacional como choque entre culturas. En el futuro, si las desigualdades continúan incrementándose, asistiremos a enfrentamientos cada vez más violentos entre excluidos $e$ incluidos, nuarginados y nuevos amos del mundo ${ }^{2 n}$. Es difícil prever las dimensiones y las consecuencias de estos fenómenos, pero no parece nada aventurado afirmar que serán imparables mediante procedimientos pacíficos, mientras sigan aumentando las enormes diferencias hoy existentes entre mundo pobre y mundo rico, entre pajses pobres y países ricos, entre regiones pobres y regiones ricas de un mismo mundo 29 .

\section{Desarme cultural y cultura planetaria}

Ante esta situación, la filosofía moral y polftica postmoderna suele declarase

25. Cfr. F. Houtart, o.p. cil., pp. 17-18.

26. Cfr. F. Fernández Buey, La gran perturbación.... p. 432.

27. Se conoce por pensamiento único "la traducción en términos ideológicos y con pretensión universal de los intereses de un conjunto de fuerzas económicas, en particular las del capital internacional", I, Ramonet. op. cit., p. 11 I; cfr. pp. 87-I16.

28. Cfr. I. Ramonet, op. cit., pp. 133-135.

29. Cfr. F. Fernández Buey, La barbarie..., p. 239. 
impolente. Contempla lo que ocurre (por ejemplo, en Yugoslavia o Argelia) como un nuevo retorno al viejo primitivismo ("esto es increíble, esto es irracional"), y no sabe dar cuenta y razón de semejantes encontronazos culturales ("esto es inexplicable en una sociedad que hace poco era predominantemente laica"). Clama en favor de la tolerancia sin percatarse que su tolerancia ilustrada sólo funciona "hacia adentro, entre gentes formalmente iguales", sólo tiene vigencia "en el marco de una cultura considerada por la generalidad que se afirma tolerante como superior, precisamente por el nivel del formación alcanzado en comparación con el de otras culturas". Cuando se asoma a las relaciones internacionales "es tolerancia en el marco de la doble moral", es decir, "autoritaria con todas aquellas manifestaciones culturales externas previamente definidas como inferiores" 30 . Que los ilustrados liberales son generalmente partidarios del mantenimiento del colonialismo o no hacen problema de su existencia puede resultar una afirmación excesivamente dura para su pedigree democrático. Pero ¿cómo podremos calificar su complicidad con la guerra del Golfo o su esiruendoso silencio ante la doble medida aplicada por el gobiemo del "vigía de occidente" en el cumplimiento de las resoluciones de Naciones Unidas según afecten a sus "civilizados" intereses (caso del embargo de Cuba) o a "los bárbaros" de los irakíes (caso del desmantelamiento del ammento)?

Occidente necesila emprender la larga travesía del "desarme cultural"."1 que le permita establecer un diálogo en igualdad de condiciones con las demás culturas de la tierra. Y no tiene más alternativa: el diálogo de la escucha de "los otros" que le hace vulnerable o el "autismo" de la fortaleza y (más) OTAN. Cada día resulta más urgente y necesario caminar en la primera dirección. Una de las paradojas de esta época histórica es que la creciente globalización del mundo va acompañada de nuevas diferenciaciones. Cosmopolitismo y particularidad no deberían ser realidades opuestas, sino complementarias. Nos encontramos en una época de diferencias entrelazadas. Tanto el imperativo de homogeneización como la terca insistencia en la propia peculiaridad viven de la misma ilusión: creer que vivimos en un mundo simple, manejable y protegido Frente a las eventualidades del devenir histórico. Sin embargo, la complejidad cultural es una de sus caraclerísticas más acusadas. Por cllo, el reciente informe dirigido a la UNESCO insiste en la necesidad de orientarse hacia una coexistencia fecunda y una armonía intercultural. Más aún, vincula la diversidad cultural al desarrollo humano. Los esfuerzos destinados a erradicar la pobreza deben incluir la dimensión cultural. No basta con ayudar materialmente a los pobres. Cada vez se postula con mayor claridad la necesidad de promover procesos a través de los cuales los pobres vayan superando su vulnerabilidad, ganando en capacidad personal y familiar para llevar a cabo cambios positivos en su situación. Entre ellos se incluye la capacidad de poder expresarse plenamente a través de la riqueza de una identidad cultural concreta, y poder participar así en la determinación del modelo de desarrollo y las medidas concretas que se puedan tomar en su nombre. Se trata de permitir el ejercicio del principio de

30. Cfr. Id. La gran perturbación.... pp. 22 y 32 .

31. Cfr. R. Panikkar. op. cil., pp. 61-63. 
autodeterminación cultural al que aspiran particularmente las minorías así como las poblaciones autóctonas, y que no implica necesariamente independencia política ${ }^{32}$.

En el tramo final de este atormentado siglo XX están proliferando los intentos de recomposición multicultural del mundo, en el que particularmente la conciencia de identidad cultural juntamente con la conciencia femenina son sus sujelos más activos. La alteridad cultural comienza a entenderse como diferencia y no como carencia, como posibilidad y no como negatividad. En el interior de la cultura de la solidaridad se va abriendo paso una idea de alteridad que exige el reconocimiento del otro como sujeto y protagonista de una historia cultural, sexual, religiosa, etc., diferenciada. Poco a poco tiende a abandonarse el ideal de la ilustración que entronizaba una humanidad abstracta. La tierra está habitada por personas concretas, negras o amarillas, varones o mujeres, salvadoreñas o vascas, hablantes del quechua o del inglés, cristianas o budistas. Cada una de esas identidades puede ser un hogar para el encuentro de los pueblos consigo mismos y con los demás, y proporcionarles las bases de poder para luchar contra la opresión y diseñar y perseguir sus propios objetivos. Pero esos hogares pueden convertirse en nidos de agtesividad y, en caso de conflicto, en campamentos bases desde donde lanzar ataques al territorio enemigo. Nuestra historia más reciente nos muestra hasta qué punto es real y peligrosa esta profunda ambivalencia".

Alentar un futuro más humano que el presente depende directamente de nuestra capacidad para vivir juntos en un único mundo, respetando y potenciando las diferencias legítimas y aboliendo las espúreas. Necesitamos aprender a asumir cordialmente el pluralismo cultural, hacerlo descansar no en la indiferencia, sino en el diálogo de las culturas, y reconocer que cada cultura tiene en sí significados de valor universal y parentesco con las otras ${ }^{34}$. El siglo XXI habrá de afrontar las tarea de salvar la extraordinaria diversidad cultural que creó la diáspora de la humanidad y, al mismo tiempo, nutrir una cultura planetaria común a todos. En esla paradójica conjunción descansa gran parte de la posibilidades de futuro de esta vieja humanidad. "Se trataría - como dice E. Morinde dirigimos hacia una sociedad universal basada en cl genio de la diversidad y no en la falta de genio de la homogeneidad... Es preciso preservar y abrir, al mismo tiempo, las culturas... Debemos defender las singularidades culturales al mismo tiempo que promovemos hibridaciones y mestizajes, debemos vincular la salvaguardia de las identidades y la propagación de una universalidad mestiza o cosmopolita, que tiende a destruir estas identidades. ¿Cómo integrar sin desintegrar?... Deseamos el desarrollo de las redes en el tejido planetario. Predicamos el mestizaje, en las condiciones en que es simbiosis y no toma de substancia de una civilización por otra. El carnet de identidad terrestre del nuevo

32. Cfr. UNESCO, op. cil., pp. 9, 62-63, 162.

33. Cfr. M. Volf, "La superación de la violencia y el papel de la religión", Concilium 272 (1997), pp. 59-60.

34. Cfr. A. Touraine, " ¿Qué es una sociedad multicultural? Falsos y verdaderos problemas". Claves 56, oclubre 1995, p. 20. 
ciudadano del mundo comporta una reunión de identidades concéntricas, comenzando por la identidad familiar, local, regional, nacional. La identidad occidental, incluso cuando haya integrado en sí misma, como es deseable, componentes nacidos en otras civilizaciones, deberá ser concebida como un componente de la identidad terrestre, y no como esa identidad. El internacionalismo quería convertir la especie en un pueblo. El mundialismo quiere hacer del mundo un Estado. Se trata de convertir la especie en una humanidad, el planeta en una casa común para la diversidad humana" ${ }^{39}$.

¿Seremos capaces de convertir en realidad este sueño en el próximo siglo?

\section{El templo de Dios: un albergue común para la diversidad humana}

El cristianismo que durante siglos fue parte del problema del conflicto y la violencia cultural está a las puertas del siglo XXI en condiciones de ser parte de su solución. Se encuentra en trance de enfrentarse con éxito a ese enorme reto tantas veces señalado por J. B. Metz, a saber: transitar de una Iglesia de cultura excesivamente monocéntrica y eurocéntrica a una Iglesia universal culturalmente policéntrica. La Iglesia cuenta con argumentos suficientes y prácticas (todavía incipientes) como para pensar que puede conseguir ser "la manifestación provisional de lo que Dios quiere para el mundo" (K. Barth). ¡Ojalá que el Espíritu Santo, "agente principal de la nueva evangelización" (TMA 44), libere a la Iglesia de la ley del uniformismo y la abra a la gracia de la diversidad!

\section{Inculturación de la fe y "contracultura" evangélica}

El concilio Valicano II reconoció que no era correcto absolutizar como normativa para todo tiempo y cultura la comprensión occidental de la fe de la misma manera que no lo fue hacerlo con la semita. Esta propuesta de relativización (más tarde ratificada y ampliada por la Evangelii Nuntiandi y la Redemptoris Missio) supone positivamente que la Iglesia debe entrar en comunión con las diversas formas culturales para evangelizarlas. El diálogo con las culturas se convierte en clave hermenéutica de la misión de la Iglesia. El concilio inaugura, activa y entrega un nuevo modo eclesial de estar en la realidad. La Iglesia se hace palabra y coloquio, como más tarde recordará Pablo $\mathrm{VI}^{16}$. Pero, además, este diálogo es necesario para ella misma, pues le permite enriquecerse con la diversidad cultural y comprender mejor el mensaje de Cristo (GS 58). La Iglesia estrena el paradigma de enriquecimiento mutuo en su relación con las culturas del mundo. Por una parte, en todas ellas -incluso en aquellas que puedan haberle sido más hostiles- puede encontrar "semillas" inéditas de su propia verdad (GS 44). Todas las culturas le anuncian "la buena nueva" cristopneumatológica que encierra la realidad en la medida en que cada una de ellas es expresión singular de la inabarcable riqueza de lo humano (GS $4 ; 11 ; 22$ ). Por otra, el evangelio, que ella ofrece y sirve, pretende contagiarlas con su talante

35. E. Morin y A. B. Kern. "Tierra-Patria", Barcelona, 1993, pp. 145-149.

36. Cfi. Ecclesiam suan 60. 
fraterno y solidario y seducirlas con un sentido de la trascendencia que, en lugar de remitirlas "más allá de las estrellas", las reenvla a "los infiernos" del mundo al encuentro del "otro": el extraño, el extranjero, el "insignificante", el excluido, el pobre. En esta comunión recíproca, la experiencia cristiana llega a expresarse con los elementos propios de las diversas culturas y se convierte en principio inspirador, normativo y unificante, que las transforma y las recrea, dando origen a una nueva creación cultural. La tarea de la inculturación de la fe consiste precisamente en establecer esta comunión dialéctica entre evangelio y cultura ${ }^{37}$.

Evangelio y culturas pueden vivir en comunión. Entre ambos existe la afinidad de lo auténticamente humano. Pero, a la vez, ese encuentro resulta purificador para los dos. La alteridad de lo diversamente humano y de lo inauténticamente humano siempre se interpone entre ellos. En cada proceso de inculturación, la fe ha de desprenderse de la figura cultural e histórica con la que va al encuentro de la nueva cultura. Pero, por su parte, reclama de toda cultura "la recepción" de lo contracultural que el evangelio del Dios de los pobres siempre trae consigo, justamente por ser verdadera y radicalmente humano y humanizador. Si finalmente se produce el encuentro buscado, el resultado será una fe redefinida de acuerdo con los nuevos contextos y dinámicas sociales que le salen al paso, y una cultura redefinida, en cuanto que en ella está presente, al menos, un colectivo humano que "tiene orra manera socialmente visible de estar en el mundo que la socialmente más generalizada" e intenta hacerla culturalmente significativa ${ }^{3 n}$.

\section{Tener buenos argumentos no es suficiente}

Un cristianismo universal y culturalmente diverso propiciará elementos preventivos de la violencia en el contexto internacional de los choques culturales, y desconstructores del poder absolutista y asimilacionista del sujeto único de la historia. Pero, además, activará factores contraculturales que liberarán la estructura dialógica de los seres humanos y hermanará a los pueblos en su diversidad cultural. Ciertamente, un cristianismo así configurado acreditará mejor que sus discursos magisteriales y teológicos su fe trinitaria. La fe en un solo Dios Padre que funda irrevocablemente en el mundo la promesa de una humanidad fraterna; la fe en Jesús, el Hijo primogénito de los hermanos, buen noticia para los pobres e imagen normativa de cómo la realización de aquella promesa va brotando y se realiza por el camino de la solidaridad kenótica con los empobrecidos; la fe en el Espíritu Santo, el medio divino que hace posible la unidad de la fraternidad

37. Cfr. M. Kehl, op. cir., pp. 230-233; A. Torres Queiruga, "Inculturación" en Floristán. C.- Tamayo, J. J. (eds.), Conceptos fundamentales de passoral, Madrid. 1983 y en Id. Conceptos fundamentales del cristianismo, Madrid. 1993. pp. 47I480 y 61 1-619, respectivamente; P. Suess, Inculturación, en I. Ellacuría,-J. Sobrino. (eds.). Mysterium Liberationis. Conceptos fundamentales de la reologia de la liberación II, Madrid. 1990, pp. 377-422.

38. Cfr. A. Tornos. "Seguimiento de Jesucristo e inculturación", en J. M. García-Lo-mas, y J. R. García-Murga. El seguimiento de Cristo. Madrid. 1997, pp. 352-356. 
en la diversidad, es decir, que todos los pueblos siga expresándose en su cultura, pero comprendiéndose entre sí (Hech 2, 6.8.1 I).

Recientemente se ha propuesto la "teología del abrazo" para resolver los conflictos entre los pueblos. Este constructo teológico se nutre de la teología trinitaria, prefiere las categorfas "exclusión" y "abrazo" a las de "opresión" y "liberación", y pretende resituar las teologías de la liberación insertándolas en un marco teológico más amplio que conserve sus puntos fuertes y elimine sus puntos débiles ${ }^{34}$. La propuesta resulta sugerente, pero, a la espera de conocerla más ampliamentc, tne pregunto si le bastará al cristianismo con contar con argumentos para alcanzar el ideal de la unidad en la diversidad y para hacer políticamente opcrativa la teología. La historia demuestra que las razones indiscutibles del cristianismo primitivo en favor del igualitarismo no impidieron ayer los desafueros del colonialismo. Entonces, las prácticas igualitarias y respetuosas con la diversidad no se desprendieron directamense de la teorla cristiana. Brotaron de un contacto cualificado (por la compasión) con la realidad colonial, que permitió redefinir la teoría cristiana. La lucha de Bartolomé de Las Casas contra la teología oficial de su (iempo está para atestiguarlo. ¿Por qué extrañas razones la cultura oficial cristiana tuvo que negarse a sí misma para dar alas a la empresa colonial? ¿Por qué Las Casas percibió con tanta claridad que cs una ralacia todo colonialismo realizado en nombre del cristianismo? ¿Qué lecciones lascasianas podemos extraer para no repetir aquella misma historia?

\section{La realidad como argumento}

La primera lección de aquel "clarividente testigo memoria lista de la gran perturbación" es que convirtió la realidad en argumento. Su pensamiento no sólo se refiere a la práctica, sino que está elaborado por alguien inserto en ella. $Y$ su modo de estar en la realidad le permite razonar sobre asuntos de Indias con mucha más lógica y más acertadamente que los teólogos españoles, por muy célebres c ilustres que sean ${ }^{40}$. Efectivamente, Bartolomé de Las Casas inspirado por el escándalo moral y recorriendo la vía empírica de "la comprobación trági$c a$, el patetismo y la compasión" en la percepción de lo que realmente estaba pasando en la colonización de América, puso en duda piezas sustanciales de su propia tradición filosófica y teológica, invirtió incluso su signo cultural, y acabó configurando un novedoso conccplo de tolerancia y compasión en nombre de los oprimidos, al que más adelante nos referiremos ${ }^{41}$.

Hay una página de su vida que ilustra magnfficamente su capacidad para dejarse argumentar por la realidad. Cuando más arrecia la polémica en torno a la barbarie o no de los indios para justificar o condenar su servidumbre, Las Casas reconocerá la distancia entre su punto de vista y el aristotélico (con el que se pretendía justificar la guerra contra los indios) con un exabrupto: "Mandemos a paseo en esto a Aristóteles, pues de Cristo, que es verdad eterna, tenemos el

39. Cfr. M. Volf. op. cit., pp. 55-62.

40. Cfr. G. Gutiérrez, En busca de los pobres.... pp. 24-26.

4I. Cfr. F. Fernández Buey. La gran perturbación.... pp. 32-33. 
siguiente mandato: 'Amarás a tu prójimo como a ti mismo' (Mateo, 22); y de nuevo Pablo dice: 'La caridad no busca lo que es suyo, sino lo que es de Jesucristo' (Epístola a los Corintios, 13)". Enfrentado a Sepúlveda, seguramente se equivoca en su interpretación del aristotelismo, pero acierta plenamente en lo sustancial: en el reconocimiento del derecho a la diferencia del otro, de la otra cultura, de los que están siendo oprimidos y expoliados, de la soberanfa de los indios sobre sus cosas. Y esto ocurre así no porque se recurre al mensaje cristiano, sino porque para decidir acerca de lo nuevo hay que tener experiencia directa de la novedad. Sepúlveda argumenta "de leídas" (o de ordas), Las Casas desde lo que han visto sus propios ojos, desde una experiencia personal prolongada en América, desde una vivencia intensa, como protagonista precisamente de una forma de entender el choque entre culturas que él está defendiendo. Paradojicamente el resultado es un pensamiento lascasiano que puede presentarse como una vuelta a los orígenes, como una recuperación del mensaje igualitario y liberador del primitivo cristianismo ${ }^{42}$.

Esta vieja historia evoca fácilmente otras polémicas mucho más próximas a nosotros en el tiempo entre teólogos que hablan de oídas y teólogos que lo hacen desde una experiencia intensa de la diferencia y de la alteridad. La perspectiva del empirismo herético lascasiano daba paso a una percepción de los hechos que, en su tiempo, fue considerada exagerada por sus compaliolas que, cinco siglos después, se ve como una descripción precisa, apasionada y moralmente motivada de los mismos ${ }^{43}$. ¿Qué teorías intocables habremos de "mandar a pasco" nosotros para que el cristianismo no vuelva a reconciliarse con la historia a destiempo? Como se nos advierte con razón. "la argumentación lascasiana muestra que una cosa es predicar el universalismo desde el Vaticano y la integración de los pueblos desde las instituciones del centro del imperio (o sea desde los poderes de la época, del momento histórico) en nombre de los principios cristianos, y otra cosa asumir esos mismos principios por identificación práctica con los oprimidos, desde la vivencia, esto es, de la identificación con el prójimo al que se trata de evangelizar e instruir"

\section{La perspectiva del otro como fuente de conocimiento}

Seguramente resulta inapropiado e innecesario denominar a Las Casas té́logo de la liberación ${ }^{45}$. Sería pecar de anacronismo. Pero si buscamos en su pensamiento algún aire de familia con esta corriente teológica, habremos de reparar en que la perspectiva del olro, del indio, en el que percibe "al pobre según el evangelio", constituyó la fuente de conocimiento que le permitio "desenterrar la verdad"4h. Las Casas lee y relee los hechos como si fuese indio. Y esto convierte su punto de vista peninsular en favorable a los derechos de los indios. Su discur-

42. Cfr. ibid.. pp. 157-164; el texto cilado se encuentra en p. 159.

43. Cfr. ibid., pp. 33-35.

44. Ibid., p. 318.

45. Cfr. G. Guliérrez, En busca..., p. 27.

46. Cfr. ibid., pp. 104-144. 
so es el de la Iglesia de los indios, del "indio melropolitano"47. Es así como realiza (a tiempo, es decir, en contemporaneidad con los hechos históricos) la primera manifestación histórica del remordimiento producido por los daños causados a la otra cultura. Es un discurso crítico con su propia cultura y combativo conıra los intereses de su país, porque entre Dios y él mismo no hay más mediación que la misión de defender a los indios contra todos ${ }^{4 x}$.

Las Casas nos invita a recoger su herencia. La contribución de la Iglesia a la resolución del choque cultural pasa por que sea más decididamente Iglesia de los pobres. Ello supone con toda seguridad criticar la cultura hegemónica de occidente, pero no desde las exigencias de la verdad (que con excesiva frecuencia se suelen identificar con las necesidades y privilegios eclesiásticos), sino desde los intereses de los pobres y las culturas agredidas. En un mundo como el nuesiro, el universalismo cristiano debería saber recoger la herencia lascasiana y converlirse en "conciencia de especie desde abajo" ". La Iglesia cuenta con suficientes argumentos cristológicos y neumatológicos para ello. La celebración del jubileo 2000 puede ser una oportunidad histórica para que subraye más decididamente en su vida lo que repite sin cesar en sus documentos: su opción preferencial por los pobres y marginados (TMA 51).

\section{El desvelamiento de la complicidad estructural}

Las Casas lue consciente de que lo que pasaba en las Indias no era solamente cuestión de las debilidades de los hijos de la Iglesia. El percibió claramente que la dimensión de los destrozos humanos y culturales producidos por la colonización dependía principalmente de la capacidad para producir muerte del sistema colonial con el que el catolicismo estaba aliado. ${ }^{*}$. El sistema socioeconómico implantado era el que producía la muerte de los pueblos indígenas. El inal estaba en el sistema que, sustentado sobre la codicia del oro, se convertía en un ídolo que exigía la victimación de los pueblos y culturas indigenas. La Iglesia y su empresa evangelizadora mantenIan complicidad con el sistema 51 .

El diagnóstico de los choques culturales ya ha dejado claro que son principalmente fruto de un sistema económico ("la sociedad de mercado"), que declara por su propia lógica superfluos a un número cada vez más creciente de sectores y pueblos de la humanidad. El discernimiento de las posibles alianzas estructurales que el cristianismo pueda tener hoy establecidas con el mercado global resultará decisivo para cumplir con su vocación de ofrecer un hogar para los que no lo tienen ${ }^{52}$. La importante doctrina social de la Iglesia y el recurso constante

47. Cfr. F. Fernández Buey, La gran perturbación..., p. 269.

48. Cfr. ibid.. p. 236.

49. Cfr. ibid., p. 318.

50. Cfr. F. Fernández Buey, La gran perrurbación..., p. 29. 247-288; G. Gutiérrez, En busca de los pobres..., p. $391-424$.

5I. Cfr. G. Gutiérrez, ibid., pp. 391 ss.

52. Cfr. J. H. Elliol, Un hogar para los que no tienen patria ni hogar. Estudio crítico social de la Carta primera de Pedro y de su situación y estrategia. Estella (Navarra). 1995. 
a ella en los documentos oficiales no garantiza sulicientemente que dichas alianzas no existan. La historia eclesial más reciente no deja ninguna duda: la Iglesia oficial ha sido mucho más sensible y beligerante hacia el "error antropológico" de las culturas agnósticas y ateas del socialismo real que con el "error tcológico". la idolatría del mercado, de la cultura occidental. El diagnóstico que olicialmente se hace de esta cultura recuerda excesivamente al de los neoconservadores norteamericanos que buscan una apertura a la trascendencia que deje como está el sistema económico y permita soportar las consecuencias de sus disfunciones.

\section{Una nueva teoría contracultural: la tolerancia lascasiana}

Según Fernández Buey, Las Casas nos ofrece un novedoso concepto de tolerancia y compasión en nombre de los oprimidos, que recoge el espíritu contracultural del evangelio de Jesús. Francisco de Vitoria había revisado la concepción aristotélica para defender los derechos de los vencidos (los indios) en el marco de la cultura de los vencedores. Bartolomé de Las Casas la revisará desde la cultura de los vencidos ${ }^{53}$. Y este matiz será decisivo a la hora de configurar un pensamiento propio. Se trata de una tolerancia que "empieza siendo piedad, compasión del otro; pero, al discutir con la propia cultura, se va haciendo radicalmente crítica de la doble moral, de la existencia de dos varas de medir las (supuestas) barbarie e ilustración de los hombres; es, pues, comprensión del otro globalmente considerado, tolerancia referida a la cultura que la generalidad considera bárbara; comprende a las otras costumbres aunque las considere bárbaras y no pueda compartir el comportamiento de los miembros de la otra cultura; es 'tolerancia' en la duda, pues pone entre paréntesis la creencia generalizada según la cual el bárbaro es sólo el otro; mantiene el mismo criterio de valoración en la estimación de todas las costumbres, pero tiene, además, conciencia histórica, que utiliza en la argumentación a favor de la comprensión de la otra cultura y en contra de los olvidos interesados relacionados con la barbarie o la crueldad de la culcura propia; no es, pues, una tolerancia relativista o cínica en el sentido de estar dispuesta a pasar por alto los aspectos deplorables de la cultura otra que trata de comprender o justificar en todo contexto, en toda discusión; al contrario: distingue y da mucha importancia a las circunstancias de la discusión, porque afirma al mismo tiempo la necesidad moral de una jerarquización de los valores y la primacía de ponerse a favor de los generalmente considerados inferiores; en última instancia, también la tolerancia preilustrada se hace intolerante en ciertos momentos cruciales: cuando no debate con los otros, esta tolerancia se hace autoritaria contra los miembros de la propia cultura que están demasiados seguros de la propia seguridad; es, en suma, tolerancia en nombre de los (comparativamente) oprimidos, de los de abajo":\$4.

No hay espacio para comentarios. Pero no importa demasiado porque el texto es suficientemente elocuente. Especialmente sugerente y aprovechable re-

53. Cfr. La gran perturbación..., p. 67.

54. Ibid., pp. 32-33. 
sulta esa idea de rolerancia en la duda, que no nace de ningún relativismo ("todo da lo mismo"), sino de la empatía con el diferente, y obliga, entre otras cosas. al diálogo de la escucha, a la crítica de la propia cultura y a la búsqueda común. No resulta nada fácil ponerla en práctica ni en el interior de la cultura dominante occidental, ni en la Iglesia. Aquélla, tras anunciar el final de "los grandes relatos" y desautorizar las utopías, vive segura en sí misma y fortificando su futuro. La Iglesia promueve una tolerancia desde la verdad y se muestra incapaz de distanciarse de su propia cultura eclesiástica y criticarla. Frecuentemente, esta dilicultad se manifiesta en la intolerancia con que, sin tener expcriencia de la novedad, se reciben y rechazan muchos de los esfuerzos por pensar con novedad la fe en contextos culturales y religiosos nuevos, que realizan las teologías de la liberación, las teologías feministas, la ética teológica y la teología de las religiones.

La tolerancia en la duda hace obviamente más vulnerable y débil a quien la practica. También más humano y consecuentemente más divino. La Iglesia no debería temer a este despojamiento que la asemeja a su Señor y la convierte en compañera de la aventura para consiruir un albergue cálido y fraterno para la diversidad humana, en el que habite Dios por su Espíritu. 